\title{
Regions and regionalism
}

\author{
Michael Keating
}

It is notoriously difficult to define the region. It is a territorial space, certainly, so we can exclude virtual spaces from our consideration, but it can take a number of territorial configurations. There is a conventional but still useful distinction between substate regionalism, studied traditionally by geographers, planners, sociologists, political scientists and historians, and supra-state regions, studied by other geographers and in international relations and strategic studies. Economists may make use of both. A third conception is the transnational region, which cuts across the boundaries of states, taking in some but not all of the territory or more than one political community. All these meanings, however, are relative to the nation-state, being above, below, or across it but not questioning its standing as the authoritative definer of territorial boundaries. Most of them also unproblematically use the term "nation-state" to define both a sovereign polity and one in which state and nation coincide, although in plurinational polities these are quite different meanings.

A more radical use of the term region dissociates it from any necessary connection with the state in general or a specific state in particular. Regions in this broader sense may be defined by functional systems, notably economic ones, by culture, by history and the interpretation of history, by political opportunity, or by institutions. Their relation to the system of states is not given a priori and is often problematic. It is this more radical interpretation of the region that has driven the revived interest in regions and regionalism in the last 20 years, including the two "new regionalisms," the one in regional economic, social, and political studies, and the other in international relations. Here regions are seen as spaces in their own right rather than as either aggregations or subdivisions of states.

Much of the drive to new regionalism comes from functional considerations. Economic change and development have escaped the bounds of the state and become global; but at the same time the specific character of particular places is ever more important in explaining economic dy- 
namism. Policy problems such as the environment and security can no longer be addressed exclusively at the state level. New systems of action and regulation have emerged at new spatial scales.

Yet we cannot reduce regions and regionalism to a mere functional logic. Functional considerations may provide reasons for rescaling; they do not constitute causes, without agents to take up these reasons and give them institutional expression. So political actors decided to create a transnational space at the level of the European Union, when transnationalization could have taken other forms. Free trade agreements in other parts of the world similarly take a specific territorial frame of reference. States across Europe have regionalized internally in order to gain traction over difficult problems that cannot be resolved at the state level, but they have done so in so many different ways that a sweeping functionalist explanation is seriously incomplete. In practice, regions are contested spaces in which there are winners and losers, depending on how they are constituted. Too much of the literature draws simply upon a traditional statist logic, in which states are portrayed as unitary actors reconstituting spaces to their own convenience. Other works, notably in the governance tradition, focus only on organizational actors, which often appear socially disembedded, again pursuing their individual interests. There are too few studies that look at how territory intersects with social and economic interests, be they defined by class, sector, or gender so that particular definitions of territory will benefit one or another group. There is more on the intersection of territory and ethnicity, although too little of this draws on more recent and sophisticated appreciations of territory, which see it as a flexible concept whose boundaries can be more tightly or more loosely defined.

Regions are contested in several ways. Their boundaries will by definition include some and exclude other individuals and groups, and this will affect their public culture and the balance of power within them. Their competences may be more tightly or broadly drawn. A conception of the region defined according to narrow economic criteria and confined to economic development will draw in economic interest groups and limit the political agenda to economics. Business groups have tended to prefer such a functionally-defined regionalism, while other interests have sought to broaden the agenda of development to include social and environmental considerations. The institutionalization of regions may also be more or less exclusive or inclusive, technocratic or democratic. There may be privately-dominated agencies; state agencies; indirectly-elected councils; intergovernmental bodies (whether within or between states); or democratically-elected governments.

The term governance has frequently been used in reference to regions, whether suprastate, substate or transnational. I have always found this 
term exasperatingly vague, but in this case it seems to be drawing attention to the fact that at these new territorial scales there is little hierarchy and little capacity for authoritative decision-making. From a normative perspective, this is a matter for concern. In a system of pluralist negotiation (which is what governance in this sense seems to amount to) the strongest will prevail. Where policy is managed by sectoral communities, larger questions about social purpose or the distributive impact of decisions may get lost. In a system of multiple levels, privileged groups, notably large businesses, can shop around for favorable treatment and access and relocate to get the best deal on taxes and regulation.

There is a danger of the disjuncture of market and economic change, which is migrating to supranational levels, and the social compensation for change, which remains the responsibility of states. National social compromises, which depended on social partners being locked into the same constraining territorial boundaries, may unravel. Regions, faced with the need to attract footloose capital at all costs, may engage in a race to the bottom.

There is, however, a counterpart to this in the politicization of the new spaces precisely in response to the dangers posed by the dominance of a particular, narrow conception of the economy. Regions have become spaces of contestation between this economic vision and a rival one based on social cohesion and environmental considerations. Kenichi Ohmae's (1995) utopia (my dystopia) of cutthroat competition among reified regions, with social considerations marginalized, will not come to pass as long as democratic processes within regions operate. For this, however, we need something more than governance. We need a reinvigorated vision of government as an authoritative system of policy-making whose ultimate test of legitimacy is democratic and inclusive rather than narrowly functional or economic. This new journal is thus well timed and promises to take the debate on regions and regionalism into new dimensions and visions.

MICHAEL KEATING is chair in Scottish politics at the University of Aberdeen. He has published extensively in the fields of European politics, nationalism, public policy, urban and regional politics and society, and social science methodologies. From 2010 until 2013 he holds professorial fellowship from the Economic and Social Research Council. From 2000 until 2010 he was professor of political and social sciences at the European University Institute, Florence, and was head of department from 2004 to 2007. His books include: The independence of Scotland: Self-government and the shifting politics of union; Culture, institutions and economic development: A study of eight European regions; and Plurinational democracy: Stateless nations in a postsovereignty era. 


\section{REFERENCES}

Ohmae, K. (1995). The end of the nation-state: The rise of regional economies. New York: The Free Press. 